\title{
Hidden yet visible: methodological challenges researching sexual health in Sudanese refugee communities
}

\author{
Judith Dean $^{\mathrm{a} *}$, Judy Wollin ${ }^{\mathrm{b}}$, Donald Stewart ${ }^{\mathrm{c}}$, Joseph Debattista $^{\mathrm{d}}$ and Marion Mitchell ${ }^{\mathrm{e}}$ \\ ${ }^{a}$ School of Nursing and Midwifery, Griffith University, Meadowbrook, Australia; ${ }^{b}$ Quality and \\ Research Unit, Wesley Mission, Brisbane, Australia; ${ }^{c}$ School of Public Health, Griffith University, \\ Chermside, Australia; ${ }^{d}$ Sexual Health and HIV Service, Queensland Health, Brisbane, Australia; \\ ${ }^{e}$ School of Nursing and Midwifery, Research Centre for Clinical and Community Practice \\ Innovation, Griffith University, Nathan, Australia
}

(Received 8 December 2011; final version received 3 July 2012)

\begin{abstract}
Research addressing sensitive topics with people from small, minority, ethnic communities can present challenges that are difficult to address using conventional methods. This paper reports on the methodological approach used to explore sexual health knowledge, attitudes and beliefs among the Sudanese community in Queensland, Australia. The multiphase, mixed-method study involved young people 16 to 24 years of age participating in a written survey and semi-structured interview and focus-group discussions with the broader Queensland Sudanese community members. Community collaboration, the key factor to the success of this research, optimised the development of a research environment that built trust and facilitated access and subsequent understanding. Research conducted in partnership with the target community can address methodological challenges and produce meaningful information when researching sensitive topics with small but 'highly-visible' populations.
\end{abstract}

Keywords: research methods; sexual health; Sudanese refugees; vulnerable populations; Australia

\section{Introduction}

Sensitive research topics require participants to discuss attitudes, beliefs and behaviours considered personal and private, which may lead to discomfort, social isolation or even persecution (Wellings, Branigan, and Mitchell 2000). Such research raises methodological, ethical and logistical difficulties as researchers and participants balance cultural and social values and ethical research considerations (Birman 2005). Addressing issues such as sexual health from a cultural perspective with a small, highly-visible, 'hard-to-reach' population has in the past resulted in the research being deemed 'too hard' to countenance (Hynes 2003;, Ogilvie, Burgess-Pinto, and Caufield 2008; Smith and Pitts 2007; Wilson and Neville 2009). These difficulties have contributed to the dearth of research addressing sensitive topics in hard-to-access groups.

This paper reports on the methodological approach used to explore the sexual-health knowledge, attitudes and behaviours of the Queensland Sudanese community. The research utilised a descriptive, collaborative multiphase research model (Creswell and Plano-Clark 2007), involving a combination of quantitative and qualitative approaches.

*Corresponding author. Email: Judith.dean@griffith.edu.au 
Emerging from a community-led initiative to understand the variance of intergenerational sexual health attitudes and beliefs, it aimed to identify and explore the sexual health knowledge, attitudes and patterns of behaviour of 16-24-year-old Queensland Sudanese community members, together with the social, cultural and contextual perspective of the broader Queensland Sudanese community.

The importance of establishing rapport and working with the community is emphasised throughout this paper. We describe the steps taken to address the methodological challenges of sampling and recruitment, along with data collection, and highlight some strategies to address the challenges associated with these key research design issues. We contend that the challenges of conducting sensitive research with small, minority, ethnic communities can be addressed with careful planning and close community collaboration.

\section{What do we know about the target population?}

The Australian Bureau of Statistics Census of Population and Housing recorded 19,050 Sudan-born people living in Australia in 2006 (Commonwealth of Australia 2009). However, it is estimated that around 28,000 people of Sudanese background have resettled in Australia since 1996 (Australian Government 2009) with approximately 62\% being under 24 years of age (Commonwealth of Australia 2007). Sudan's history of over 40 years of civil conflict (Rogier 2005) has led to the majority of Sudanese community members arriving in Australia via the Humanitarian Program following protracted periods of displacement and forced migration (Commonwealth of Australia 2007). The longevity of Sudan's civil conflict also means many young Sudanese arrivals have never known life without unrest and the range of physical, psychological and social experiences that accompany forced migration and life in a refugee camp (Tempany 2009). These experiences may include trauma, torture, rape, family separation and loss, and community breakdown, along with limited access to education and health services (Copping, Shakespeare-Finch, and Paton 2010; Goodman 2004; Kizito 2001; Tempany 2009).

It is well established that forced migration is associated with sexual health vulnerabilities and increased risk of negative sexual-health outcomes (McGinn 2000). Despite this, there is scant research addressing sexual health and well-being of migrant and refugee communities in their new settlement country (Hoffman et al. 2011; McMichael and Gifford 2009; Tompkins et al. 2006, Zhou 2012). As the sexual health of refugee background communities continues to be overlooked post-resettlement in Australia (McMichael and Gifford 2010), the authors of this paper argue that this group's sexual vulnerability may continue after resettlement if the lack of research and understanding continues.

An emerging body of research involving members of the Australian Sudanese community focuses mainly on this community as a part of larger collective target populations such as African (Harte, Childs, and Hastings 2009; Johnson 2007; Matereke 2009; Neale et al. 2007; Sheikh-Mohammed et al. 2006) or refugee groups (Henderson and Kendall 2011; Johnson, Ziersch, and Burgess 2008) and thus limits specific understanding of this community group. Some of these broader studies include HIV status among minority ethnic groups (Körner 2007) and working with African communities on HIV prevention (Lemoh, Biggs, and Hellard 2008). However, studies with the Australian Sudanese community as the sole target population mainly focus on issues pertaining to acculturation (Hebbani, Obijiofor, and Bristed 2009; Milner and Khawaja 2010; Poppitt and Frey 2007), settlement in Australia (Lejukole 2008; Murray 2010; Nunn 2011), English language literacy and learning (Brown, Miller, and Mitchell 2006; 
Burgoyne and Hull 2007), mental health and trauma (Copping, Shakespeare-Finch, and Paton 2010) and not sexual health.

In contrast to this trend, McMichael (2008) explored sexual-health literacy among 16-25-year-old refugee youth in Melbourne and identified a number of key factors that influence the sexual health of this group. However, the small sample $(n=142)$ prohibited meaningful analysis of the Sudanese sub-group $(n=25)$ data (McMichael 2008). Poor HIV knowledge and patterns of sexual-risk behaviour have been found in studies conducted with Sudanese communities in Sudan (Ali and Pett 2005; Allen 2007) and resettlement countries such as the USA (Tompkins et al. 2006; Willis and Nkwocha 2006). However, the dearth of studies focusing on sexual health knowledge, attitudes and behaviours within unique sociocultural contexts of individual resettlement communities continues to limit our ability to respond with appropriate interventions.

\section{Researching sensitive topics with a highly-visible community}

The Queensland Sudanese community, like other refugee-background communities, may in some senses be considered 'hidden' and 'hard-to-reach' (Jacobsen 2006; Spring et al. 2003). Pre-arrival experiences, including mistrust of government-initiated programmes, may result in a reluctance to participate in research (Gifford et al. 2007; Hynes 2003). Fear that participating in research focusing on a socially and culturally sensitive topic may further add to discrimination and negative stereotyping already experienced post-settlement and create further unwillingness (Colic-Peisker 2009; Ogilvie, Burgess-Pinto, and Caufield 2008; Wilson and Neville 2009). Both these factors contribute to this group being considered hidden and hard-to-reach. However, while potentially hard-to-reach, the Queensland Sudanese community, due to their physical, racial and cultural characteristics, may be considered 'highly visible' rather than hidden, within the predominately 'white Anglo-Western' Australian community (Colic-Peisker 2009; Colic-Peisker and Tilbury 2007; Dhanji 2009; Hebbani and McNamara 2010; Nunn 2011; White 2009). Despite Australia's multiculturalism and anti-discrimination policy and legislation, visibly different individuals and communities experience discrimination and negative stereotyping (Colic-Peisker 2009; Colic-Peisker and Tilbury 2007). Fear of further discrimination, if associated with sensitive research, combined with a reluctance to participate in research due to past experiences may present difficulties when conducting research with this group.

Highly-visible communities are also often labelled as belonging to a collective, homogenous group by appearance and/or experiences (Dhanji 2009; White 2009). For example the Sudanese community may be labelled 'African' (Dhanji 2009) and/or, 'refugee' (Nunn 2011), as in the studies conducted in Australia noted earlier. A collective grouping labelled as refugee can create: feelings of isolation and not belonging within the Australian community; an increased sense of vulnerability and stigmatisation; and generalisation of pre- and post-arrival experiences (Nunn 2011). Collective labelling as African has the potential for researchers with limited understanding of the true heterogeneous nature of the African and Sudanese community to miss recognising the needs of specific ethnic sub-communities with their target population (Dhanji 2009). Failure to recognise unique target population characteristics may impact on a researcher's ability to gain access and trust within the community (Wilson and Neville 2009). The success of any research with a highly-visible or hidden minority group depends on the researcher developing a level of rapport that enables sharing of these unique nuances and the sociocultural reality of participants (Wilson and Neville 2009). Research questions related to participants' sexual health involves the exploration of personal and sensitive 
issues and this can be particularly challenging with communities who identify this topic as culturally taboo and/or sensitive (Elam and Fenton 2003). As it is the community and individual participants who can most effectively define issues that are sensitive and identify methods to address these issues, one of the most effective ways to address the challenge of researching potentially sensitive issues is to incorporate the target community in the development of the research approach (Elam and Fenton 2003). In this study, community consultation indicated that the desire to develop greater understanding of what young people were thinking and doing in regards to relationships and sexual behaviour and how the community needed to respond, outweighed the traditional sensitivity toward sexual health.

\section{Study design and methods}

This paper draws from an exploratory descriptive multiphase research project, which emanated from extensive community consultation and a pilot study phase. Conducted under ethical approval from Griffith University Human Research Ethics committee (GU Ref No: NRS/02/09/HREC), this project used a concurrent converging triangulation mixed-method approach (Creswell and Plano-Clark 2007) that involved the concurrent separate collection and analysis of data relating to the same phenomenon from three independent primary-data sources. These included (1) a cross-sectional written sexual health survey with 16-24-year-old, self-identifying members of the Queensland Sudanese community $(n=229)$, (2) 11 semi-structured interviews with a sub-sample of the survey participants and (3) five community focus-group discussions with 19 adults aged between 25 and 51 years. The data from these phases were then triangulated without transformation, via a process of comparing and contrasting separate findings (Creswell and Plano-Clark 2007). Identification of convergent and divergent themes provided a depth of findings that effectively answered the research questions and increased confidence in the meaning and trustworthiness of the study findings (Creswell and PlanoClark 2007). The combination of quantitative and qualitative approaches to investigate this complex and sensitive topic provided rich data (Sandelowski 2000) and strengthened the quality and rigour of findings (Ager 2000; Creswell 1994; Creswell and Plano-Clark 2007; Moffat et al. 2006). The process adopted provided a better understanding of the overlapping complexity of issues that is often lacking in single method studies (Creswell and Plano-Clark 2007).

\section{Community consultation and study reference group}

Widespread community consultation occurred prior to commencing the study and was ongoing throughout. This helped to develop understanding of the social and cultural context of the community and foster community trust and identification with the research (Israel et al. 2005) while providing opportunity to identify their needs (Israel et al. 2005; Lantz et al. 2006;Sadler et al. 2006; Wallerstein et al. 2005). The chief researcher, this paper's first author, consulted with the community by the formation of a study reference group of community members combined with regular attendance at formal community meetings and participation in informal social gatherings. The researcher established an open, respectful communication pathway, both face-to-face and via telephone and email contact, with the reference group and other key community members to ensure the community had a direct voice in the research. 
The reference group, comprising community members aged 19-50 years from a range of Sudanese tribal affiliations, provided cultural advice to the researcher. This group was an active partner in the development of the research question and methodological approach. Membership in the reference group changed throughout the research in response to members' varying levels of availability due to competing family, community and work demands. This diversity and fluidity of membership provided the opportunity for increased community involvement and enlarged the overall community representation. It also prevented any member becoming a gatekeeper or sole voice representing the broader community (Temple and Moran 2006).

Community involvement included not only the establishment of the reference group but ongoing support and input from members of key Queensland Sudanese formal groups and a number of informal social networks. An email group comprising community members and participants, who expressed an interest in being kept informed of the study's progress, provided a pathway for the reverse flow of information about community issues and upcoming events, for disseminating research information and study recruitment. Young members of the reference group and the extended email consultation process provided valuable input into the development of a youth-friendly and safe research environment. It also enabled recruitment strategies that targeted youth from a range of community subgroups to be implemented. Creating a connection between the research, the young people and the broader target community was instrumental in the successful engagement and recruitment for this study.

The first author spent a considerable time attending community and youth-specific gatherings. This provided opportunity to observe and gain understanding of the cultural beliefs, traditions and sociocultural reality of the community's Queensland experience. Drawing on previous research (Cottone 2005; Harte, Childs, and Hastings 2009; Hebbani, Obijiofor, and Bristed 2010; Khawaja et al. 2008; Murray 2010; Poppitt and Frey 2007; Westoby 2008) and anecdotal evidence gathered during the various consultations, she developed a closer understanding of the multi-layered issues that face the target community and its young members in their new social world. This understanding, combined with ongoing collaboration with the reference group, guided development of a contextually and culturally appropriate research environment (Westoby 2008; Wilson and Neville 2009).

While logistically time consuming and sometimes challenging, time spent engaging in community consultation was essential. Without this active partnership with the community and invaluable sharing of information, it would not have been possible to develop a research approach reflective of these participants' sociocultural reality (Israel et al. 2005; Nyamathi, Koniak-Griffin, and Greengold 2007; Temple and Moran 2006). This approach was essential as it was acceptable to, and inclusive of, the target population and built a level of trust and rapport that facilitated recruitment of adequate participant numbers in a culturally appropriate environment, thereby, minimising selection bias and maximising research value (Birman 2005; Smith and Pitts 2007; Spring et al. 2003). This research partnership model supported the development of findings that would be perceived as relevant and meaningful to the study participants, along with service providers and heath policy makers (Gifford et al. 2007; Wilson and Neville 2009).

\section{Why do a pilot study?}

The pilot study phase determined feasibility of accessing the target community and the appropriateness of the methodological approach. It allowed for early identification of 
barriers or cultural practices that could hinder the research process and timely revision of the research process if required (VanTeijlingen and Hundley 2001). A convenience sample of 30 tribally diverse 16-24-year-old members of the target community was recruited into the pilot phase to assess the sexual health survey for cultural and linguistic appropriateness. This also provided an opportunity for broader consultation with young members of the community. In addition, it resulted in changes to recruitment strategies including incorporating peer recruiters as active participants in recruitment and data collection, together with the inclusion of sporting and social organisations as the primary access and recruitment sites. One community focus-group discussion with five adult members aged between 25 to 40 years was also conducted in the pilot phase. Focusgroup discussions have been found to be acceptable and effective in eliciting data on social norms when researching sexual-health- and cross-cultural-related issues (Connell, McKevitt, and Low 2004; Culley, Hudson, and Rapport 2007; Temple and Moran 2006). Findings from this pilot group gave further insight into the research question, language skill, levels of community interest and accessibility and guided refinement of the focus-group discussion guide.

\section{Sample}

Sudan consists of over 50 heterogeneous ethnic groups, with approximately 140 different spoken languages (Kizito 2001) along with a complex and diverse array of religious and regional affiliations and sub-communities (Jensen and Westoby 2008; Moro 2004). To date, these demographics have not been captured in any Australian population data, making it difficult to define a clear sample frame for this study. Community consultation indicated that being Sudanese was not based on place of birth or language spoken as recorded on Australia census data. Therefore, for the purpose of eligibility for this research, Sudanese was defined as any person who self-identified as being Sudanese. This reflected the community's view on 'being' Sudanese.

Sample sizes for the interview and focus- group data collection were determined by exhaustion of emerging themes. Calculating and achieving a sample size for the survey phase posed some challenges. Based on the estimated population size of 16-24-year-old Sudanese Queenslanders, an established Needed Sample Sizes table (Reaves 1992) indicated a sample size between 230 to 240 participants was needed with an alpha of 0.05 . As this represents nearly $50 \%$ of the total 16-24-year-old population, there was a concern that this may place unrealistic demand on the participants and community. Initial assessment of the logistics, cost and feasibility also indicated tha it may have been beyond the timeframe and capacity of the research. A timeframe of 12 months was therefore set for survey data collection, when recruitment numbers would be reviewed.

\section{Sampling and recruitment}

Non-probability convenience sampling, including snowball and purposive sampling in conjunction with multiple active strategies of recruitment, was chosen as the most culturally and methodologically appropriate approach for this research (Ahmed, Hussain, and Vournas 2001; Bloch 2007; Schofield 2004). Regular consultation with peer recruiters, reference-group members and participants allowed adjustment of sampling methods and active recruitment strategies to reflect local demographics. Purposive sampling was applied in order to achieve gender balance and inclusion of social and tribal/familial networks reflective of the broader Queensland Sudanese community structures. This further increased 
the probability that the findings were reflective of the generalised normative beliefs and concerns of the wider community (Elam and Fenton 2003).

Distribution of information and recruitment of participants focused on established cultural, social, sporting and family networks given that strong bonds within these networks are generally formed early upon resettlement (Sheikh-Mohammed et al. 2006). Hidden and hard-to-reach populations also gather at known places (Magnania et al. 2005) and in this instance peer recruiters, study reference-group members and past participants guided the researcher to these known gathering points. This further extension of the seeding points increased opportunity for members of smaller more hidden networks to participate (Magnania et al. 2005).

Recruitment of adults for the focus-group discussions was mainly through convenience sampling, using established community groups such as women's support groups, community-based organisation networks and community forums and social events that the researcher was invited to attend.

Two young members of the reference group, one female and one male, acted as peer recruiters and were pivotal to the successful recruitment of young people for the survey and interview phases. The use of peer recruiters was strongly supported by both community feedback and the literature as a culturally-appropriate and communityaccepted means to facilitate access (Correa-Velez et al. 2011; Elliott, Watson, and Harries 2002; Luchters et al. 2008; Simon and Mosavel 2010; Vargo et al. 2004). The peer recruiters were from two different social, tribal and geographical groups within the community and thus were able to provide a diversity of peers and social networks to begin seeding for snowball sampling and recruitment. The use of peer recruiters also decreased the risk of overrepresentation of any one group as they continued to identify new diverse seeding points throughout the data-collection period. This included some state-wide sporting events involving African youth, World Refugee Day celebrations and formal social gatherings organised by the community association. All locations were noted as acceptable and safe by the peer recruiters, the reference group and community leaders. The researcher gave the peer recruiters information about important aspects of the study to support them in their role in recruiting eligible potential participants and data collection. This was successful and 229 participants were recruited by this process within the 12-month timeframe mentioned earlier, thus achieving the previously considered unobtainable task of recruiting an adequate sample size.

\section{Data collection}

The data collection tools for the study were consistent with Fishbein's Integrated Behaviour Science Theory model (Fishbein 2000), the theoretical approach adopted for this research. The sexual-health survey and discussion guides for both the interviews and focus groups were developed from the 4th National Survey of Australian Secondary Students HIV/AIDS and Sexual Health (Smith et al. 2009) for comparison purposes. Reviewed for cultural and linguistic suitability in consultation with the reference group and during the pilot study, the data collection tools were adjusted accordingly. Care was taken not to change the intent of the survey questions. The Cultural Identity Schedule validated in the RELACHS study (Institute of Community Health Sciences 2003) was added to the sexual-health survey to capture cultural identity data.

Data collection occurred in English. While it is acknowledged poor English literacy and language skills could be a barrier, English is widely spoken in Southern Sudan (Adult Migrant English Programme Research Centre 2003) and community consultation 
indicated that the general English proficiency would be adequate amongst potential participants. The reference group considered the use of interpreters may, in fact, reduce participants' willingness to disclose sensitive information (Fenton et al. 2002) and affect group dynamics (Culley, Hudson, and Rapport 2007). This was supported by findings from the pilot focus group. The peer recruiters and researcher also assisted eligible participants to complete the sexual-health survey when requested, thereby increasing participation of young people with lower English skills, who may otherwise have been excluded.

\section{Addressing the challenges of community data collection}

Many African cultures are polychromic, placing less emphasis on adhering to schedules and more importance on meeting the needs of the people they are with at the time, often interacting with multiple people at once (Hall 2012). To the more monochronic Australian culture, where people tend to arrange their lives around schedules, polychronic cultures can appear spontaneous and unstructured. In this study, this manifested itself in the manner in which participants often arrived late for scheduled meetings, which were further interrupted due to arrival of family or friends. Prior understanding of this cultural norm ensured additional time was allocated for data collection and meetings. However, the time spent waiting for participants to arrive was not wasted as it provided time to observe and converse with community members who arrived near the scheduled starting time. The sharing of stories over a cup of tea provided additional insight into social and cultural attitudes and beliefs of the community, thus further deepening the researcher's understanding and strengthening community rapport.

Polychronic cultures also place great meaning on family and gathering in groups and this can lead to difficultly establishing a quiet place to meet for data collection (Hall 2012). To adjust for the Sudanese polychronic nature, the interviews and focus groups were also kept flexible in nature so that participants could join late and come and go as needed. For example Sudanese women are the main care givers (Wal 2004), therefore young children were often present, requiring the discussion to be stopped to allow for participants to address their children's needs. This also posed some difficulty in recording the discussion as there was often significant background noise. To address this, a skilled medical transcriber with knowledge of cross-cultural research was used to transcribe the digital recordings. Additional time was also allocated to checking audio recordings with written field notes and transcripts by the researcher to check accuracy and ensure the intent was captured.

The researcher was also flexible in scheduling and changing meeting times and place to meet study participants' needs. For example, men and young participants were generally less available during the day due to work and school commitments, meetings were therefore scheduled for evenings and weekends. For the additional convenience for participants, data collection often occurred in homes and locations nominated by the participants. This provided a relaxed and safe environment to facilitate the sharing of information (Gallagher 2009; Holloway and Wheeler 2010). However, consideration needed to be given to the potential risks associated with community-based data collection and a safety plan was developed in consultation with the community and the research team and adhered to at all times (Dickson-Swift et al. 2007).

\section{Discussion}

Careful planning, cultural understanding and sensitivity, and close community collaboration can overcome the methodological challenges associated with conducting 
sensitive research with small, highly-visible ethnic minority communities. The research methodology needs to be acceptable and appropriate to the community and aligned with the community's sociocultural context (Wilson and Neville 2009). The research needs to reflect the voice and socialcultural reality of the target community and the only way to achieve this is to design and conduct the research in collaboration with the community (Elam and Fenton 2003; Ogilvie, Burgess-Pinto, and Caufield 2008; Wilson and Neville 2009).

The perception of a community as hard-to-reach may be an artefact of conventional research practices, limited understanding of the cultural diversity in heterogeneous groups and limited experience in collaborating and conducting research with these groups. Sampling and recruitment present real challenges, but there is a range of communityinclusive approaches that enable the culturally appropriate recruitment of participants. Research with small, highly-visible ethnic minority communities requires that research participants know that their voices are heard and included. Researchers must be committed to engage the community throughout the research process.

Involving the community and using peer recruiters undoubtedly added complexity and additional ethical considerations, but addressing the challenges was feasible and rewarding to the community, participants and the researchers. Mutuality, in terms of sharing and respect of cultural beliefs and research knowledge, is a first step to developing a culturally-appropriate environment and research methodology where the community and researchers are equal partners and beneficiaries of the research. This can only be achieved by ensuring the target community is involved in all stages of the research, as was the case of the research outlined in this paper. However, it is also important to ensure that the community partners understand the research aims and processes and are kept informed of progress and outcomes in a manner they consider beneficial to participants and the broader community (Culley, Hudson, and Rapport 2007). The reciprocal sharing of experiences and outcomes can reduce misunderstanding, disillusion and reluctance to participate.

More sexual-health research, conducted in collaboration with small but highly-visible communities, is needed. Without this, community members may not receive appropriate sexual-health care and education. The key to developing specific services and supporting health policy is for researchers and target communities to work together to address the challenges associated with this type of research in a mutually reflective way.

\section{Acknowledgements}

The first author is currently conducting the research outlined in this paper as part of a Doctoral degree at Griffith University, Australia. The study was supported by the Queensland Nursing Council Novice Researcher Grant (RAN 1034) and the Centaur Memorial Fund for Nurses Scholarship. The authors acknowledge the support and guidance provided by the Ethnic Communities Council of Queensland, especially Zhihong Gu. The authors thank the members of the Queensland Sudanese Communities for their support and participation. In particular, the authors acknowledge the invaluable cultural advice and support of the reference group and the enthusiastic contribution of the peer recruiters Johnston Aleer and Sanyu Labajo Luru.

\section{References}

Adult Migrant English Programme Research Centre. 2003. Country profile factsheet 4 - Sudan. Melbourne, VIC: La Trobe University.

Ager, A. 2000. Psychological programs: Principles and practice for research and evaluation. In Psychosocial wellness of refugees: Issues in qualitative and quantitative research, ed. F.L. Ahern, 24-38. New York: Berghahm Books. 
Ahmed, S., M. Hussain, and G. Vournas. 2001. Consultation with 'hidden' and hard-to-reach groups: Methods, techniques and research practice. Paper presented at Consulting Hard To Reach Groups: Laria Seminar, November 15, in Birmingham, UK.

Ali, M., and C. Pett. 2005. A sexual and reproductive health education initiative for young Sudanese refugees in urban Egypt. Community Development Journal 40, no. 2: 192-200.

Allen, T. 2007. Witchcraft, sexuality and HIV/AIDS among the Azande of Sudan. Journal of Eastern African Studies 1, no. 3: 359-96.

Australian Government. 2009. Refugee and humanitarian issues Australia's response June 2009. Canberra: Department of Immigration and Citizenship.

Birman, D. 2005. Ethical issues in research with immigrants and refugees. In The handbook of ethical research with ethnocultural populations and communities, ed. J.E. Trimble and C. Fisher, 155-78. Thousand Oaks, CA: Sage.

Bloch, A. 2007. Methodological challenges for national and multi-sited comparative survey research. Journal of Refugee Studies 20, no. 2: 230-47.

Brown, J., J. Miller, and J. Mitchell. 2006. Interrupted schooling and the acquisition of literacy: Experiences of Sudanese refugees in Victorian secondary schools. Australian Journal of Language and Literacy 29, no. 2: 150-62.

Burgoyne, U., and O. Hull. 2007. Classroom management strategies to address the needs of Sudanese refugee learners: Support document - methodology and literature review. Adelaide, SA: National Centre for Vocational Education Research.

Colic-Peisker, V. 2009. Visibility, settlement success and life satisfaction in three refugee communities in Australia. Ethnicities 9, no. 2: 175-99.

Colic-Peisker, V., and F. Tilbury. 2007. Refugees and employment: The efect of visible difference on discrimination. Perth, WA: Centre for Social and Community Research, Murdoch University.

Commonwealth of Australia. 2007. Sudanese community profile. Canberra: Department of Immigration and Citizenship.

Commonwealth of Australia. 2009. Community information summary: Sudan-born. Canberra: Department of Immigration and Citizenship.

Connell, P., C. McKevitt, and N. Low. 2004. Investigating ethnic differences in sexual health: Focus groups with young people. Sexually Transmitted Infections 80, no. 4: 300-5.

Copping, A., J. Shakespeare-Finch, and D. Paton. 2010. Towards a culturally appropriate mental health system: Sudanese-Australians' experiences with trauma. Journal of Pacific Rim Psychology 4, no. 1: 53-60.

Correa-Velez, I., A.G. Barnett, S.M. Gifford, and D. Sackey. 2011. Health status and use of health services among recently arrived men with refugee backgrounds: A comparative analysis of urban and regional settlement in south-east Queensland. Australian Journal of Primary Health 17, no. 1: 66-71.

Cottone, C. 2005. New kids on the block: Making space for Sudanese young people in Queensland. West End, QLD: Youth Affairs Network of Queensland.

Creswell, J.W. 1994. Research design qualitative and quantitative approaches. Thousand Oaks, CA: Sage.

Creswell, J.W., and V.L. Plano-Clark. 2007. Designing and conducting mixed methods research. Thousand Oaks, CA: Sage.

Culley, L., N. Hudson, and F. Rapport. 2007. Using focus groups with minority ethnic communities: Researching infertility in British South Asian communities. Qualitative Health Research 17, no. 1: $102-12$.

Dhanji, S. 2009. Welcome or unwelcome? Integration issues and the resettlement of former refugees from the horn of Africa and Sudan in metropolitan Melbourne. Australasian Review of African Studies 30, no. 2: 152-78.

Dickson-Swift, V., E.L. James, S. Kippen, and P. Liamputtong. 2007. Doing sensitive research: What challenges do qualitative researchers face? Qualitative Research in Psychology 7, no. 3: $327-53$.

Elam, G., and K.A. Fenton. 2003. Researching sensitive issues and ethnicity: Lessons from sexual health. Ethnicity and Health 8, no. 1: 15-27.

Elliott, E., A.J. Watson, and U. Harries. 2002. Harnessing expertise: Involving peer interviewers in qualitative research with hard-to-reach populations. Health Expectations 5, no. 2: 172-8. 
Fenton, K., M. Chinouya, O. Davidson, and A. Copas. 2002. HIV testing and high-risk sexual behaviour among London's migrant African communities: A participatory research study. Sexually Transmitted Infections 78, no. 4: 241-5.

Fishbein, M. 2000. The role of theory in HIV prevention. AIDS Care 12, no. 3: 273-8.

Gallagher, M. 2009. Data collection and analysis. In Researching with children and young people: Research design, methods and analysis, ed. E.K.M. Tisdall, J.M. Davis, and M. Gallagher, 65-153. Los Angeles, CA: Sage.

Gifford, S.M., C. Bakopanos, I. Kaplan, and I. Correa-Velez. 2007. Meaning or measurement? Researching the social contexts of health and settlement among newly-arrived refugee youth in Melbourne, Australia. Journal of Refugee Studies 20, no. 3: 414-40.

Goodman, J.H. 2004. Coping with trauma and hardship among unaccompanied refugee youths from Sudan. Qualitative Health Research 14, no. 9: 1177-96.

Hall, E.T. 2012. Monochronic and polychronic time. In International communication: A reader, ed. L.A. Samovar, R.E. Porter, and E.R. McDaniel. 13th ed. Boston, MA: Wadsworth, Centage Learning.

Harte, W., I.R.W. Childs, and P.A. Hastings. 2009. Settlement patterns of African refugee communities in southeast Queensland. Australian Geographer 40, no. 1: 51-67.

Hebbani, A., and J. McNamara. 2010. Examining the impact of 'visible difference' on multiple marginalisation of Somali and Sudanese former refugees in Australia. Paper presented at the Australian and New Zealand Communications Association Annual Conference, July 7-9, in Canberra, Australia.

Hebbani, A., L. Obijiofor, and H. Bristed. 2009. Generational differences faced by Sudanese refugee women settling in Australia. Intercultural Communication Studies 18, no. 1: 66-82.

Hebbani, A., L. Obijiofor, and H. Bristed. 2010. Intercultural communication challenges confronting female Sudanese former refugees in Australia. Australasian Review of African Studies 31, no. 1: $37-61$.

Henderson, S., and E. Kendall. 2011. Culturally and linguistically diverse peoples' knowledge of accessibility and utilisation of health services: Exploring the need for improvement in health service delivery. Australian Journal of Primary Health 17, no. 2: 195-201.

Hoffman, S., J.A. Higgins, S.T. Beckford-Jarrett, M. Augenbraun, K.E. Bylander, J.E. Mantell, and T.E. Wilson. 2011. Contexts of risk and networks of protection: NYC West Indian immigrants' perceptions of migration and vulnerability to sexually transmitted diseases. Culture, Health and Sexuality 13, no. 5: 513-28.

Holloway, I., and S. Wheeler. 2010. Qualitative research in nursing and healthcare, 3rd ed. Oxford: Wiley-Blackwell.

Hynes, T. 2003. New issues in refugee research. The issue of 'trust' or 'mistrust' in research with refugees: Choices, caveats and considerations for researchers. Working paper 98. Geneva: Evaluation and Policy Analysis Unit, The United Nations Refugee Agency.

Institute of Community Health Sciences. 2003. Health of young people in East London: The relachs study 2001. London: TSO.

Israel, B.A., E. Eng, A.J. Schulz, and E.A. Parker. 2005. Introduction to methods in communitybased participatory research for health. In Methods in community-based participatory research in health, ed. B.A. Israel, E. Eng, A.J. Schulz, and E.A. Parker, 3-26. San Francisco, CA: Jossey-Bass.

Jacobsen, K. 2006. Refugees and asylum seekers in urban areas: A livelihoods perspective. Journal of Refugee Studies 19, no. 3: 273-86.

Jensen, P., and P. Westoby. 2008. Restorative justice: An integrated model for resettling young Sudanese. New Community Quarterly 6, no. 3: 13-19.

Johnson, D. 2007. Rates of infectious diseases and nutritional deficiencies in newly arrived African refugees. Adelaide, SA: Government of South Australia.

Johnson, D.R., A.M. Ziersch, and T. Burgess. 2008. I don't think general practice should be the front line: Experiences of general practitioners working with refugees in South Australia. BMC Australia and New Zealand Health Policy 5, no. 20. doi: 10.1186/1743-8462-5-20

Khawaja, N.G., K.M. White, R. Schweitzer, and J. Greenslade. 2008. Difficulties and coping strategies of Sudanese refugees: A qualitative approach. Transcultural Psychiatry 45, no. 3: 489-512.

Kizito, H. 2001. Refugee health care: A handbook for health professionals. Wellington: New Zealand: Ministry of Health Wellington. 
Körner, H. 2007. Negotiating cultures: Disclosure of HIV-positive status among people from minority ethnic communities in Sydney. Culture, Health \& Sexuality 9, no. 2: 137-52.

Lantz, P.M., B.A. Israel, A.J. Schulz, and A. Reyes. 2006. Community-based participatory research: Rationale and relevance for social epidemiology. In Methods in social epidemiology, ed. J.M. Oakes and J.S. Kaufman, 239-66. San Francisco, CA: Jossey-Bass.

Lejukole, J.WK.L. 2008. 'We will do it our own way': A perspective of Southern Sudanese refugees resettlement experiences in Australian society. Adelaide, SA: The University of Adelaide.

Lemoh, C., B. Biggs, and M. Hellard. 2008. Working with West African migrant communities on HIV prevention in Australia. Sexual Health 5, no. 4: 313-4.

Luchters, S., M.F. Chersich, A. Rinyiru, M.-S. Barasa, N. King'ola, K. Mandaliya, W. Bosire, S. Wambugu, P. Mwarogo, and M. Temmerman. 2008. Impact of five years of peer-mediated interventions on sexual behavior and sexually transmitted infections among female sex workers in Mombasa, Kenya. BMC Public Health 8, no. 143. doi: 10.1186/1471-2458-8-143

Magnani, R., K. Sabin, T. Saidel, and D. Heckathorn. 2005. Review of sampling hard-to-reach and hidden populations for HIV surveillance. AIDS 19, suppl. 2: S67-72.

Matereke, K. 2009. 'Embracing the aussie identity': Theoretical reflections on challenges and prospects for African-Australian youths. Australasian Review of African Studies 30, no. 1: $129-43$.

McGinn, T. 2000. Reproductive health of war-affected populations: What do we know? International Family Planning Perspectives 26, no. 4: 174-80.

McMichael, C. 2008. Promoting sexual health amongst resettled youth with refugee backgrounds. Melbourne, VIC: Refugee Health Research Centre, La Trobe University.

McMichael, C., and S. Gifford. 2009. 'It is good to know now ... before it's too late': Promoting sexual health literacy amongst resettled young people with refugee backgrounds. Sexuality \& Culture 13, no. 4: 218-37.

McMichael, C., and S. Gifford. 2010. Narratives of sexual-health risk and protection amongst young people from refugee backgrounds in Melbourne, Australia. Culture, Health \& Sexuality 12, no. 3: $263-77$.

Milner, K., and N.G. Khawaja. 2010. Sudanese refugees in Australia: The impact of acculturation stress. Journal of Pacific Rim Psychology 4, no. 1: 19-29.

Moffat, S., M. White, J. Mackintosh, and D. Howel. 2006. Using quantitative and qualitative data in health services research: What happens when mixed methods findings conflict? BMC Health Services Research 6, no. 28. Doi: 10: 1186/1472-6963-6-28. http://www.biomedcentral.com/ content/pdf/1472-6963-7-85.pdf

Moro, L.N. 2004. Interethnic relations in exile: The politics of ethnicity among Sudanese refugees in Uganda and Egypt. Journal of Refugee Studies 17, no. 4: 420-36.

Murray, K.E. 2010. Sudanese perspectives on resettlement in Australia. Journal of Pacific Rim Psychology 4, no. 1: 30-43.

Neale, A., J.Y.Y. Ngeow, S.A. Skull, and B. Biggs. 2007. Health services utilisation and barriers for settlers from the Horn of Africa. Australian and New Zealand Journal of Public Health 31, no. 4: $333-5$.

Nunn, C. 2011. Spaces to speak: Challenging representations of Sudanese-Australians. Journal of Intercultural Studies 31, no. 2: 183-98.

Nyamathi, A., D. Koniak-Griffin, and B. Greengold. 2007. Development of nursing theory and science in vulnerable populations research. In Annual review of nursing research, ed. A. Nyamathi and Koniak-Griffin. 25, 3-25.

Ogilvie, L.D., E. Burgess-Pinto, and C. Caufield. 2008. Challenges and approaches to newcomer health research. Journal of Transcultural Nursing 19, no. 1: 164-73.

Poppitt, G., and R. Frey. 2007. Sudanese adolescent refugees: Acculturation and acculturative stress. Australian Journal of Guidance and Counselling 17, no. 2: 160-81.

Reaves, C.C. 1992. Quantitative research for the behavioural sciences. New York: John Wiley \& Sons.

Rogier, E. 2005. No more hills ahead? The Sudan's tortuous ascent to heights of peace. Clingendael security paper no. 1. The Hague: Netherlands Institute of International Relations, Clingendael.

Sadler, K.E., C.A. McGarrigle, G. Elam, W. Ssanyu-Sseruma, G. Othieno, O. Davidson, D. Mercey, J.V. Parry, and K.A. Fenton. 2006. Mayisha II: Pilot of a community-based survey of sexual attitudes and lifestyles and anonymous HIV testing within African communities in London. AIDS Care 18, no. 4: 398-403. 
Sandelowski, M. 2000. Focus on research methods: Combining qualitative and quantitative sampling, data collection and analysis techniques in mixed-method studies. Research in Nursing \& Health 23, no. 3: 246-55.

Schofield, M. 2004. Sampling in quantitative research. In Handbook of research methods for nursing and health science, ed. V. Minichiello, G. Sulivan, K. Greenwood, and R. Axford. 2nd ed., 176-209. Frenchs Forest, NSW: Pearson Education, Australia.

Sheikh-Mohammed, M., C.R. MacIntyre, N.J. Wood, J. Leask, and D. Isaacs. 2006. Barriers to access to health care for newly resettled Sub-Saharan refugees in Australia. Medical Journal of Australia 185, no. 11-12: 594-7.

Simon, C., and M. Mosavel. 2010. Community members as recruiters of human subjects: Ethical considerations. American Journal of Bioethics 10, no. 3: 3-11.

Smith, A., P. Agius, A. Mitchell, C. Barrett, and M. Pitts. 2009. Secondary students and sexual health 2008: Results of the 4th National survey of Australian secondary students, HIV/AIDS and sexual health. Melbourne, VIC: Australian Research Centre in Sex, Health \& Society, La Trobe University.

Smith, A., and M. Pitts. 2007. Researching the margins: An introduction. In Researching the margins strategies for ethical and rigorous research with marginalised communities, ed. M. Pitts and A. Smith, 3-41. Basingstoke, UK: Palgrave Macmillan.

Spring, M., J. Westermeyer, L. Halcon, K. Savik, C. Robertson, D.R. Johnson, J.N. Butcher, and J. Jaranson. 2003. Sampling in difficult to access refugee and immigrant communities. Journal of Nervous \& Mental Disease 19, no. 12: 813-9.

Tempany, M. 2009. What research tells us about the mental health and psychosocial wellbeing of Sudanese refugees: A literature review. Transcultural Psychiatry 46, no. 2: 300-15.

Temple, B., and R. Moran. 2006. Introduction. In Doing research with refugee: Issues and guidelines, ed. B. Temple and R. Moran, 1-20. Bristol, UK: The Policy Press, University of Bristol.

Tompkins, M., L. Smith, K. Jones, and S. Swundell. 2006. HIV-education needs among Sudanese immigrants and refugees in the midwestern United States. AIDS and Behaviour 10, no. 3: 319-23.

Van Teijlingen, E.R., and V. Hundley. 2001. The importance of pilot studies. In Social research update issue 35, ed. N. Gilbert. Guildford, UK: University of Surrey.

Vargo, S., G. Agronick, L. O'Donnell, and A. Stueve. 2004. Using peer recruiteres and orasure to increase HIV testing. American Journal of Public Health 94, no. 1: 29-31.

Wal, N.D. 2004. Southern Sudanese culture. Melbourne, VIC: Migrant Information Centre.

Wallerstein, N., B. Duran, M. Minkler, and K. Foley. 2005. Developing and maintaining partnership with communities. In Methods in community-based participatory research for health, ed. B.A. Israel, E. Eng, A.J. Schulz, and E.A. Parker, 31-51. San Francisco, CA: Jossey-Bass.

Wellings, K., P. Branigan, and K. Mitchell. 2000. Discomfort, discord and discontinuity as data: Using focus groups to research sensitive topics. Culture, Health \& Sexuality 2, no. 3: 255-67.

Westoby, P. 2008. Developing a community-development approach through engaging resettling Southern Sudanese refugees within Australia. Community Development Journal 43, no. 4: 483-95.

White, R. 2009. Ethnic diversity and differential policing in Australia: The good, the bad and the ugly. Journal of International Migration and Integration 10, no. 4: 359-75.

Willis, M.S., and O. Nkwocha. 2006. Health and related factors for Sudanese refugees in Nebraska. Journal of Immigrant and Minority Health 8, no. 1: 19-33.

Wilson, D., and S. Neville. 2009. Culturally safe research with vulnerable populations. Comtemporary Nurse 33, no. 1: 69-79.

Zhou, Y.R. 2012. Changing behaviours and continuing silence: Sex in the post-immigration lives of mainland Chinese immigrants in Canada. Culture, Health \& Sexuality 14, no. 1: 87-100. 